NBER WORKING PAPER SERIES

THE OPTIMAL USE OF FINES AND IMPRISONMENT

\author{
A. Mitchell Polinsky \\ Steven Shavell
}

Working Paper No. $\underline{932}$
NATIONAL BUREAU OF ECONOMIC RESEARCH 1050 Massachusetts Avenue
Cambridge MA 02138

July 1982

The research reported here is part of the NBER's research program in Law and Fconomics. Any opinions expressed are those of the authors and not those of the National Bureau of Economic Research. 


\section{The optimal Use of Fines and Imprisonment}

\section{Abstract}

This paper examines the use of fines and imprisonment to deter individuals from engaging in harmful activities. These sanctions are analyzed separately as well as together, first for identical risk-neutral individuals and then for two groups of risk-neutral individuals who differ by wealth. When fines are used alone and individuals are identical, the optimal fine and probability of apprehension are such that there is some "underdeterrence." If individuals differ by wealth, then the optimal fine for the high wealth group exceeds the fine for the low wealth group. When imprisonment is used alone and individuals are identical, the optimal imprisonment term and probability may be such that there is either underdeterrence or overdeterrence. If individuals differ by wealth, the optimal imprisonment term for the high wealth group may be longer or shorter than the term for the low wealth group. When fines and imprisonment are used together, it is desirable to use the fine to its maximum feasible extent before possibly supplementing it with an imprisonment term. The effects of risk aversion on these results are also discussed.

\begin{abstract}
A. Mitchell Polinsky Stanford Law School Stanford University Stanford, CA 94305
\end{abstract}

(415) 497-0886
Steven Shavell

Harvard University Law School Langdel1 260

Cambridge, MA 02138

(617) $495-7920$ 


\section{Introduction}

This paper builds upon the work of Becker (1968) in analyzing the use of fines and imprisonment to deter individuals from engaging in harmful activities. $1 /$ The optimal use of these sanctions is examined in a model in which it is assumed that fines are socially costless, that imprisonment is socially costly, and that regardless of which sanction is used, the apprehension of individuals is socially costly. $\underline{2}$ / The sanctions are analyzed separately as well as together, first for identical risk-neutral individuals and then for two groups of risk-neutral individuals who differ by wealth.

The main conclusions of the paper can be briefly summarized. When fines are used alone and individuals are identical, the optimal fine equals their weal $\operatorname{th}^{3}$ / and the optimal probability of apprehension is such that there is some "underdeterrence." If individuals differ by wealth, then the fine for the high wealth group should exceed the fine for the low wealth group. This is because it is optimal to underdeter some individuals in the low wealth group, but this underdeterrence can be reduced at no social cost for individuals in the high wealth group by raising the fine for them.

When imprisonment is used alone and individuals are identical, the optimal imprisonment term and the optimal probability may be such that there is either underdeterrence or overdeterrence. If individuals differ by wealth, the optimal imprisonment term for the high wealth group may be 
longer or shorter than the term for the low wealth group. The explanation is that, on the one hand, a given level of deterrence can be achieved by a shorter imprisonment term imposed on individuals in the high wealth group; on the other hand, because of this, it is socially cheaper to achieve a given level of deterrence for the higher wealth group and therefore it may be worthwhile to employ imprisonment to a greater extent for that group. 4 /

When fines and imprisonment are used together, the only additional point is that, regardless of whether individuals are identical, it is desirable to use the fine to its maximum feasible extent before possibly supplementing it with an imprisonment term. $5 /$ This is simply because fines are socially costless while imprisonment is socially costly.

At the end of the paper we discuss informally how the conclusions would be modified if individuals were risk averse. The main difference is that, in general, the levels of the sanctions should be lower and the probability of apprehension should be higher than for risk neutral individuals in order to reduce the bearing of risk. 


\section{The Mode1 $6 /$}

Individuals are assumed to be risk neutral and to be identical except, possibly, in terms of their wealth. Each individual faces a probability distribution of private gain from engaging in an activity which imposes harm on others. That is, what an individual would gain from engaging in the activity depends on random factors but is known to him before he has to decide whether to engage in it. (For example, the gain to an individual from falsely reporting his taxable income may depend on his need to purchase medical services.) If an individual engages in the activity, he faces some probability of being caught and fined and/or imprisoned. An individual will engage in the activity if his private gain exceeds the expected sanction.

The following notation will be used to describe this situation more precisely, where the gain and the harm are assumed to be monetary or to have monetary equivalents, and the imprisonment term is assumed to have a monetary equivalent.

$\begin{array}{ll}\mathrm{y} & \begin{array}{l}\text { initial wealth (subscripts will be used } \\ \text { when wealth differs among individuals) }\end{array} \\ \mathrm{g} & \text { gain to an individual from engaging in } \\ \text { the activity } & \text { probability density of gains } \\ \mathrm{H}(\cdot) & \text { cumulative distribution of gains } \\ \mathrm{e} & \text { external cost or harm due to engaging in } \\ \overline{\mathrm{g}} & \text { the activity }\end{array}$




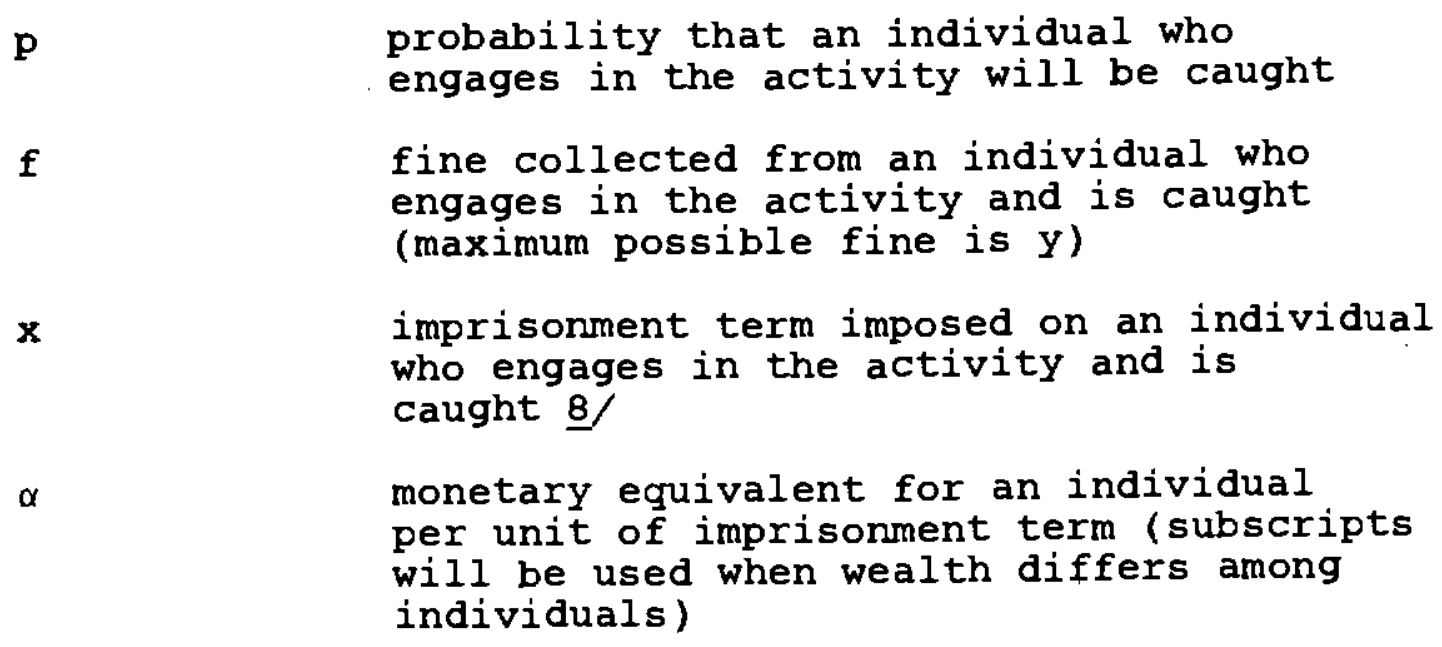

Given this notation, an individual will engage in the activity when

(1) $g>p(f+\alpha x) \cdot \frac{9}{}$

Thus, since the population size is normalized and set equal to one, $[1-H(p(f+\alpha x))]$ individuals will engage in the activity.

As noted in the introduction, it is also assumed that there is a cost to the public of imprisonment, namely the cost of operating the jail system:

$$
\begin{array}{ll}
\text { cost to the public per unit } \\
\text { of imprisonment term. }
\end{array}
$$

However, it is assumed that there is no cost to the public of imposing fines. Regardless of the sanction used, there is a cost of apprehending individuals:

$$
\begin{aligned}
& c(p) \text { cost to the public of catching fraction } \\
& \text { p of individuals who engage in the } \\
& \text { activity }\left(c^{\prime}>0\right) \text {. }
\end{aligned}
$$


Social welfare is assumed to equal the sum of expected utilities of individuals who, recall, are risk neutral. Fines paid by individuals will not directly affect social welfare because the loss of utility of the individuals paying the fines is exactly offset by the gain in utility of the individuals receiving the fine revenue. (of course, fines affect social welfare indirectly through their effect on individuals' decisions whether to engage in the activity.) Thus, social welfare $w$ equals the gains from engaging in the activity less the harm done, less the cost of catching individuals, and less the private and public cost of imprisonment: $10 /$

$$
\text { (2) } \begin{aligned}
w= & \int_{p(f+\alpha x)}^{\bar{g}} g h(g) d g-e[1-H(p(f+\alpha x))] \\
& -c(p)-(\alpha+\beta) p x[1-H(p(f+\alpha x))] .
\end{aligned}
$$

The problem to be considered in this paper is the maximization of social welfare through the choice of the fine $f$, the imprisonment term $x$, and the probability of detection $p$. The optimal values of the variables will be indicated by an "*", and we will assume that these values are uniquely determined by the relevant first-order conditions. 


\section{Fines and Imprisonment when Individuals are Identical}

In this section we will first consider the optimal use of fines and imprisonment separately, and then the optimal use of the sanctions together.

A. Fines Alone $(x=0) \underline{11 /}$

It is well known that when individuals are risk neutral, the optimal fine, $f *$, equals their wealth, $y$. If this were not true, it would be possible to raise the fine and lower the probability so as to achieve the same expected sanction at a lower cost. To be precise, suppose that $\mathrm{f}^{\star}<\mathrm{y}$ and let $k=p * f *$. By raising $f$ to $y$ and lowering $p$ to $k / y$, the expected fine is unaffected, so that the number of individuals engaging in the activity remains the same. Therefore, the only effect on social welfare is through the cost of catching individuals, which falls. Since, then, social welfare rises, $f^{*}<y$ could not have been optimal.

Given that $f^{*}=y$, the optimal probability is determined by maximizing social welfare (2) with respect to p. The resulting first-order condition can be written as

(3) $(e-p y) \frac{d H(p y)}{d p}=c^{\prime}(p)$.

The right-hand side of this condition is, of course, the marginal cost of raising the probability. The left-hand side is the marginal benefit of raising the probability, 
which equals the reduction in the number of individuals engaging in the activity, $d H(p y) / d p$, times the harm caused by each net of benefits gained (at the margin), e - py. Note that (3) implies that e - py > 0; in other words, it is optimal to have some degree of "underdeterrence". in the sense that some individuals who engage in the activity obtain gains less than the harm they cause. To understand why this is so, suppose $f=y$ and $p=e / y$ so that the expected fine equals $e$ and there is no underdeterrence. Then, by reducing $p$ slightly the cost of enforcement is lowered. Although the reduction in $p$ now leads the marginal individuals to engage in the activity, there is no (first-order) effect on social welfare because they had been receiving gains equal to e (since $\mathrm{pf}=\mathrm{e})$. Thus, it is optimal to lower $\mathrm{p}$ to some extent. $12 /$

B. Imprisonment Alone $(f=0)$

Given the probability $p$ of catching individuals, the optimal imprisonment term is determined by the first-order condition with respect to $x$ :

$$
\begin{aligned}
(e-p \alpha x) \frac{d H(p \alpha x)}{d x} & =(\alpha+\beta) p[1-H(p \alpha x)] \\
& -(\alpha+\beta) p x \frac{d H(p \alpha x)}{d x} .
\end{aligned}
$$

The right-hand side of (4) is the marginal cost of increasing the length of imprisonment and equals the private and public cost of longer terms of those individuals already in jail, 
$(\alpha+\beta) \mathrm{p}[1-\mathrm{H}(\mathrm{p} \alpha \mathrm{x})]$, less the savings in the private and public cost of imprisonment due to a reduced number of individuals who engage in the activity and are caught, $(\alpha+\beta) p x d H(p \alpha x) / d x$. The left-hand side of $(4)$ is the marginal benefit of increasing the imprisonment term and equals the reduction in the number of individuals engaging in the activity, $d H(p \alpha x) / d x$, times the harm caused by each net of benefits gained, e - pax.

Note that (4) implies that there may be underdeterrence or overdeterrence (since the right-hand side may be positive or negative). In other words, it may be the case that some individuals engaging in the activity obtain gains that are less than the harm they cause, or that some individuals who are deterred from engaging in the activity would have received gains greater than the harm they would have caused. To understand why this is so, suppose the imprisonment term is at a level such that $\mathrm{px}=\mathrm{e}$. Since there is then no (firstorder) effect on social welfare due to changes in the behavior of the marginal individuals, $x$ should be changed in the direction that reduces the private and public cost of imprisonment. Lowering $\mathrm{x}$ reduces the cost of imprisonment per person in jail but increases the number of persons in jail. If the former effect is more important than the latter effect, then it will be desirable to lower $x$. Otherwise, it will be preferable to raise $x . \underline{13} /$

The optimal probability is determined by the following first-order condition: 
(5) $\begin{aligned}(e+(\alpha+\beta) x-p \alpha x) \frac{d H(p \alpha x)}{d p} & =c^{\prime}(p)+ \\ & (\alpha+\beta) x[1-H(\alpha x)] .\end{aligned}$

The interpretation of this condition is similar to that of condition ( 3 ) determining the optimal probability in the case of fines alone. However, now the benefit of a reduction in the number of individuals engaging in the activity due to an increase in the probability includes a savings in the private and public costs of imprisonment, $(\alpha+\beta) x$. Also, the cost of an increase in the probability now includes an increase in the private and public cost of imprisonment due to the apprehension of a greater fraction of those engaging in the activity, $(\alpha+\beta) \times[1-H(\alpha x)]$.

\section{Fines and Imprisonment}

Assuming that both fines and imprisonment may be used to affect individuals' behavior, it is always optimal first to use a fine to the fullest extent possible--equal to individuals' wealth, as in the case of fines alone--before possibly supplementing it with an imprisonment term. The reason for this is simply that because the fine is a socially costless means of enforcement, it is advantageous to use it to its limit before using a socially costly means of enforcement.

To demonstrate this, suppose, to the contrary, that $f *<y$ and $x^{*}>0$. Then the expected sanction is $p\left(f^{*}+\alpha x^{*}\right)$. Now lower $x$ slightly and raise $f$ slightly so as to hold 
constant the expected sanction. The only effect on social welfare (2) is to reduce the private and social cost of imprisonment, $(\alpha+\beta) p x[1-H(p(f+\alpha x))]$. Thus, the optimal fine cannot be less than wealth if imprisonment is used. We have already shown that if imprisonment is not used, the fine should also equal wealth.

If it is optimal to supplement a fine with an imprisonment term, the choices of the probability and the imprisonment term are determined by first-order conditions with interpretations similar to those in the cases of fines and imprisonment alone. 
IV. Fines and Imprisonment When Individuals Differ by wealth

In this section we will reexamine the optimal use of fines and imprisonment when individuals have different levels of wealth. For simplicity, it is assumed that there are only two levels of wealth, $y_{1}<y_{2}$; let $\lambda$ be the fraction of individuals with wealth $y_{1}$. It is also assumed that the sanctions can differ for the two groups--denoted by subscripts on $f$ and on $x$--but that the probability of apprehension is the same for both groups. 14/ It is further assumed that the private cost of imprisonment is lower for the low wealth group, that is, $\alpha_{1}<\alpha_{2}, \underline{15}$ Thus, social welfare now is

$$
\begin{aligned}
W= & \lambda \int g h(g) d g+(1-\lambda) \int g h(g) d g \\
p\left(f_{1}+\alpha_{1} x_{1}\right) & p\left(f_{2}+\alpha_{2} x_{2}\right) \\
& -e\left[\lambda\left(1-H\left(p\left(f_{1}+\alpha_{1} x_{1}\right)\right)\right)\right. \\
& \left.+(1-\lambda)\left(1-H\left(p\left(f_{2}+\alpha_{2} x_{2}\right)\right)\right)\right] \\
& -c(p)-\lambda\left(\alpha_{1}+\beta\right) p x_{1}\left[1-H\left(p\left(f_{1}+\alpha_{1} x_{1}\right)\right)\right] \\
& -(1-\lambda)\left(\alpha_{2}+\beta\right) p x_{2}\left[1-H\left(p\left(f_{2}+\alpha_{2} x_{2}\right)\right)\right] .
\end{aligned}
$$

\section{A. Fines Alone}

It will be shown that the optimal fine for the low wealth group is equal to their wealth and that the fine for the high wealth group is larger but not necessarily equal to their wealth. The reasoning behind this result can be explained roughly as follows. By an argument similar to that used in the previous section, it will first be demonstrated that the fine for the lower wealth group is equal to 
their wealth and that there is underdeterrence of this group. Thus, if the fine were the same for the higher wealth group, they too would be underdeterred. Since it is obviously possible to impose a larger fine on the higher wealth group, the underdeterrence of this group can be reduced at no social cost. However, because raising the fine to their wealth might result in overdeterrence of them, it may not be desirable to raise the fine to that level.

To demonstrate that $f_{1} *=y_{1}$, assume, to the contrary, that $f_{1} \star<y_{1}$. Suppose first that $f_{2} *<y_{2}$. Now consider a $p$ slightly less than $p *$ and an $f_{1}$ and an $f_{2}$ slightly greater than $f_{1}$ * and $f_{2} *$, respectively, such that $p f_{1}=p * f_{1}$ * and $\mathrm{pf}_{2}=\mathrm{p}^{\star f_{2}}$ *. (It is possible to raise $f_{1}$ and $f_{2}$ since $f_{1} *<y_{1}$ and $f_{2} *<y_{2}$, since the expected sanction is the same under $p, f_{1}$ and $f_{2}$ and since $p<p^{*}$, social welfare must have risen, which contradicts the presumed optimality of $f_{1} *<y_{1}$. Now suppose that $f_{2} *=y_{2}$. Observe first that $p \star f_{2} *$ must be less than or equal to $e$. This is because if $p \star f_{2} \star>e$, then social welfare would clearly be increased by a reduction in $f_{2}$ to the point where $p \star f_{2}=e$. Since $p^{\star} y_{2}=$ $p * f_{2} \star \leqq e$ and $y_{1}<y_{2}$, it must be that $p * y_{1}<e$. Thus, social welfare could be increased by raising $f_{1}$ from $f_{1}$ * $<y_{1}$ to $\mathrm{Y}_{1}$.

To show that $f_{2} *>f_{1} *=y_{1}$, assume, to the contrary, that $f_{2} \star \leqq y_{1}$. Suppose first that $f_{2} *<y_{1}$. Note that $p^{\star} y_{1} \leqq e$ since otherwise social welfare could be increased by lowering $f_{1}$ from $y_{1}$. This implies that $p * f_{2} *<e$. But 
this would allow social welfare to be improved by raising $f_{2}$ from $f_{2} *<y_{1}$. Now suppose that $f_{2} *=y_{1}$. Then, by (3), $p^{*}$ must be such that $p^{*} y_{1}<e^{16 /}$ But this would also allow social welfare to be increased by raising $f_{2}$ from $f_{2} *=y_{1} \cdot \underline{17}$ Given $f_{1} *=y_{1}$ and given $f_{2}$, the optimal probability is determined by

$$
\lambda\left(e-p y_{1}\right) \frac{d H\left(p y_{1}\right)}{d p}+(1-\lambda)\left(e-p f_{2} *\right) \frac{d H\left(p f_{2} *\right)}{d p}=c^{\prime}(p)
$$

which has an interpretation analogous to that of (3). Since $c^{\prime}(p)>0$, it must be that $\left(e-p y_{1}\right)>0$ and/or $\left(e-p f_{2} *\right)>0$. Since $f_{2} *>y_{1}$, for sure $\left(e-p y_{1}\right)>0$. The term (e $\left.-p f_{2}{ }^{*}\right)$ may be positive, implying underdeterrence of the high wealth group, or may equal zero.

\section{B. Imprisonment Alone}

Given the probability of catching individuals, two first-order conditions analogous to (4) determine the optimal imprisonment terms for the low and high wealth groups. The imprisonment term for the high wealth group might be less than the term for the low wealth group. This possibility reflects the fact that in order to achieve a given expected sanction, the required imprisonment term for the high wealth group is less than the required term for the low wealth

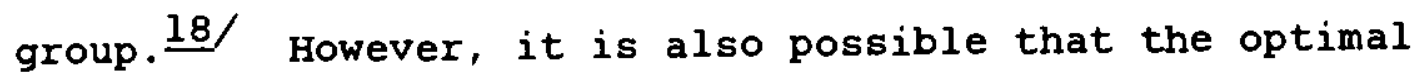
imprisonment term is greater for the higher wealth group. This might occur because imprisonment is a more "cost- 
effective" deterrent of the wealthy group--to achieve a given level of deterrence, the private cost of imprisonment is the same for both groups but the public cost is less for the wealthier group since a shorter imprisonment term is required for them. $\underline{19 /}$

Given the two imprisonment terms, the optimal probability is determined by a first-order condition analogous to (5), with a similar interpretation.

\section{Fines and Imprisonment}

If both fines and imprisonment are used, then for each group it is always optimal first to use a fine--equal to the wealth of the members of that group--before possibly supplementing it with an imprisonment term. The reason is the same as the one discussed in the previous section when there was only one group of individuals; since the proof is virtually identical, it is omitted. Also, the first-order conditions determining the optimal imprisonment terms, if they are positive, and the first-order condition determining the optimal probability are similar to those discussed in the previous section and have similar interpretations. 
v. The Implications of Risk Aversion

If individuals are risk averse, then one woul 1 expect that the optimal sanction--whether a fine or an imprisonment term--would be lower than it would be if individuals were risk neutral and that the optimal probability of apprehension would be higher. This is because the problem of maximizing social welfare would have to take into account the risk imposed on individuals subject to the sanction. $20 /$

Assuming that aversion to risk decreases with income, one would also expect that the optimal fine imposed on the high wealth group would be even larger relative to the fine imposed on the low wealth group than when individuals are risk neutral. The reason for this is that because the high wealth group is less risk averse, it is optimal for there to be less of a reduction in the level of the sanction from the level that would be appropriate if individuals were risk neutral.

Finally, if individuals are risk averse, the point that fines should be used to their fullest possible extent before imprisonment is used is not affected. The explanation is the same as when individuals were assumed to be risk neutral. 


\section{$\underline{\text { References }}$}

Becker, Gary S. "Crime and Punishment: 'An Economic Approach," J. P. E. 76, no. 2 (March/April 1968): 169-217.

Block, Michael K., and Robert C. Lind. "Crime and Punishment Reconsidered," J. Legal Stud. 4, no. 1 (January 1975a): 241-47.

Block, Michael K., and Robert C. Lind. "An Economic Analysis of Crimes Punishable by Imprisonment," J. Legal stud. 4, no. 2 (June 1975b): 479-92.

Cooter, Robert. "Deterrence and Incapacitation: Control Theory Applied to Crime," unpublished manuscript (October, 1981).

Elzinga, Kenneth G., and William Breit. The Antitrust Penalties: A study in Law and Economics. New Haven: Yale University Press, 1976.

Friedman, David. "Should the Rich Pay Higher Fines?" unpublished manuscript (August, 1980).

Polinsky, A. Mitchell. "Private Versus Public Enforcement of Fines," J. Legal stud. 9, no. 1 (January 1980): 105-27. 
Polinsky, A. Mitchell, and steven shavell. "The Optimal Tradeoff between the Probability and Magnitude of Fines," A. E. ‥ 69 , no. 5 (December 1979): 880-91.

Posner, Richard A. "Optimal Sentences for White-Collar Criminals," American Criminal Law Review, 17, no. 4 (Spring 1980$): 409-18$.

Posner, Richard A. Economic Analysis of Law. Boston: Little, Brown and Company, 2nd Edition, 1977. 


\section{Footnotes}

* Law School and Economics Department, stanford University, and National Bureau of Economic Research.

** Law School, Harvard University, and National Bureau of Economic Research. Both authors' work on this paper was supported by a grant (SOC 78-20159) from the National science Foundation to the law and economics program of the National Bureau of Economic Research. Any opinions are those of the authors and not those of the NBER. We are grateful to Frank Easterbrook, Richard Posner, and Gregory sidak for helpful comments.

1) To our knowledge, the only other formal analyses which deal with fines and imprisonment are by Block and Lind (1975a, 1975b), Cooter (1981), and Friedman (1980). Block and Lind, however, do not focus on the optimal choice of sanctions. There are also several informal discussions of fines and imprisonment that are related to our analysis, including Elzinga and Breit (1976, pp. 112-138) and Posner (1977, pp. 164-72; 1980).

2/ Of course, it is not literally true that fines are socially costless, although it is reasonable to assume that they are much less costly than imprisonment. The assumption that fines are socially costless is made for simplicity. 
3/ That the optimal fine equals an individual's wealth under the assumption of risk neutrality was first demonstrated by Becker (1968).

4/ Our conclusions regarding imprisonment are similar in spirit to those of Friedman (1980) regarding fines which are socially costly to impose.

5/ This conclusion is consistent with Becker's (1968, pp. 193-98) argument for fines over imprisonment. Posner (1980) also makes this point forcefully in the context of "white collar crime", and it is one of the main points in Cooter (1981).

6/ The model used here is similar to those used in Polinsky and Shavell (1979) and in Polinsky (1980).

7) If $\bar{g} \leqq e$, which is to say that engaging in the activity is never socially beneficial, most of the results to be discussed would not be affected. See notes 12,13 , and 17 below.

8/ For simplicity, we ignore issues of time-discounting of the imprisonment term and the fact that there is a ceiling on the length of time a person can be imprisoned. 
9) When $g=p(f+\alpha x)$, individuals are indifferent between engaging in the activity and not. We will assume that they do not. This assumption obviously will not affect our results.

10/ To show that (2) equals the sum of expected utilities, let $t$ be the per capita tax necessary to finance the cost of catching individuals and the public cost of imprisonment net of the fine revenue collected:

$$
t=c(p)+\beta p x[1-H(p(f+\alpha x))]-p f[1-H(p(f+\alpha x))] .
$$

Also, let d be the expected harm suffered by each individual (it is assumed that each individual is equally likely to be the victim of someone else's harm):

$$
d=e[1-H(p(f+\alpha x))] \text {. }
$$

Thus, the expected utility of a representative individual is

$$
\int_{p(f+\alpha x)}^{\bar{g}} g h(g) d g-d-t-p(f+\alpha x)[1-H(p(f+\alpha x))] .
$$

since the population has been normalized, this is also the sum of expected utilities. substituting the expressions for $d$ and $t$ leads directly to (2).

11) This subsection draws on Polinsky (1980, p. 111).

12) Note that if $\bar{g}<e$, there may not be underdeterrence because it may be optimal to set the probability high enough to deter everyone. 
13/ Note that if $\bar{g}<e$, by definition there cannot be overdeterrence.

14. The justification for these assumptions is that it would seem to be more difficult to design a system of detection which distinguishes among individuals on the basis of their wealth than to apply sanctions based on individuals' wealth.

15. The motivation for this assumption is that, since wealth and income are positively correlated, the income foregone due to imprisonment is likely to be smaller for a low wealth individual than for a high wealth individual.

16/ If the fine is the same for both groups, then it is straightforward to show from (6) that the problem of the optimal choice of $\mathrm{p}$ and $\mathrm{f}$ is identical to the problem that led to (3).

17. If $\overline{\mathbf{g}}<\mathrm{e}$, it may be optimal to completely deter both groups, which, since the probability is the same for both groups, would be accomplished by using the same fine for each group (equal to $Y_{1}$ ).

18/ To illustrate the possibility that the imprisonment term for the high wealth group, $x_{2}$, may be less than the term for the low wealth group, $x_{1}$, suppose $\beta=0$. Then social welfare (6) may be written in the form 


$$
w=\lambda z\left(\alpha_{1} x_{1}\right)+(1-\lambda) z\left(\alpha_{2} x_{2}\right),
$$

where $z$ is an appropriate function. clearly, if $\mathbf{w}$ is maximized with respect to $x_{1}$ and $x_{2}$, it must be that $\alpha_{1} x_{1} *=\alpha_{2} x_{2} *$. since $\alpha_{1}<\alpha_{2}, x_{2} *<x_{1} *$.

19) To see why $x_{2}$ * may exceed $x_{1} *$, suppose that $\alpha_{1}=0$ and $\alpha_{2}>0$. Then clearly $x_{1}$ * equals zero and $x_{2}$ * may exceed zero.

20/ To see this point in the case of fines, see Polinsky and Shavell (1979). 